\title{
O DISCURSO CAPITALISTA DE MARX A LACAN: ALGUMAS CONSEQUÊNCIAS PARA O LAÇO SOCIAL
}

Rosane Zétola Lustoza

Professora adjunta da Universidade Estadual de Londrina (UEL); doutora em Teoria Psicanalítica pela UFRJ.
RESUMO: Investigam-se algumas consequências geradas pelo discurso capitalista no laço social. Tomando como ponto de partida a obra de Karl Marx e o ensino de Jacques Lacan, buscou-se caracterizar o capitalismo, enfatizando a acumulação da mais-valia como um movimento sem ponto de basta, deixando o sujeito num estado de insatisfação constante, e este estado, em contrapartida, vem sempre acompanhado pelo gozo de algum gadget. O caráter ilimitado desse processo acarreta uma modificação na relação do sujeito com a natureza, com os outros homens e com ele mesmo, em que tudo se transforma em mercadoria. O sujeito passa a habitar um mundo previamente condenado a tornar-se dejeto.

Palavras-chave: Discurso capitalista, laço social, mais-valia, Marx, Lacan.

ABSTRACT: The capitalist speech from Marx to Lacan: some consequences for the social bond. The article investigates the consequences of the capitalist discourse for the social bond. Taking the works of Karl Marx and Jacques Lacan as point of departure, one aimed to characterize capitalism emphasizing the accumulation of surplus-value as a movement without point of enough that causes in the subject a state of constant insatisfaction that on the other hand is always followed by the enjoyment of some gadget. The limitless character of this process causes an modification on the relationship of the subjetc with the nature, with the other men and with himself, where everything becomes commodities. The subject starts to inhabit a world previoulsy condamned to become a deject.

Keywords: Capitalist discourse, social bond, surplus-value, Marx, Lacan. 
P retende-se investigar algumas consequências do discurso capitalista para o laço social. Considerando que em suas formulações sobre o discurso capitalista Lacan inspirou-se fortemente em Marx, buscou-se na obra deste último subsídios para uma caracterização daquele discurso. Tal procedimento se justifica, uma vez que o próprio Lacan defendia a tese de uma homologia entre os conceitos de mais-valia e mais-gozar.

Pressupor que haveria pontos de convergência entre os dois pensamentos não significa reduzir ou subordinar uma teoria à outra, até porque são pensamentos que tentam tornar inteligíveis campos distintos de problemas - a realidade social, no caso de Marx, e a realidade psíquica, no caso de Lacan. Seria demasiado grosseiro não reconhecer que se trata de obras caracterizadas cada qual por uma rede própria de conceitos. Contudo, o reconhecimento da especificidade de cada uma não deve nos impedir de enxergar uma possível compatibilidade lógica entre elas.

Iniciamos com uma síntese da tese marxista sobre a mais-valia, procurando ressaltar de que modo a extração de mais-valia funciona no modo de produção capitalista. Num segundo momento, procuraremos demonstrar a homologia entre mais-valia e mais-gozar, para em seguida apontar algumas consequências do discurso capitalista sobre o laço social. Tais consequências serão analisadas segundo duas vertentes: a da relação do sujeito com o seu trabalho e de sua relação com o consumo.

\section{A TESE MARXISTA DA MAIS-VALIA}

Investigando a origem da riqueza no capitalismo, Marx toma como ponto de partida de sua análise a forma elementar dessa riqueza, a mercadoria. O que é uma mercadoria? A primeira característica de qualquer mercadoria é ser um objeto que, "por suas propriedades, satisfaz necessidades humanas, seja qual for a natureza, a origem delas, provenham do estômago ou da fantasia” (MARX, 1867/2004, p.57). Desse modo, toda mercadoria deve possuir valor-de-uso, satisfazendo às necessidades dos indivíduos em um grupo social particular.

Apesar de a utilidade de um objeto ser condição para trocá-lo com outros, este uso não pode servir como critério para estabelecer seu preço. Isso porque a utilidade de uma mercadoria é um fator meramente qualitativo, não se prestando à quantificação: não podemos avaliar numericamente o quanto são úteis um carro, uma roupa ou uma bicicleta, pois seus usos não são comparáveis. Posso achar que uma roupa vale muito por julgá-la bela, enquanto outra pessoa consideraria a mesma roupa tão feia que não estaria disposta a pagar um centavo por ela. Ou seja, os usos de um objeto dependem exclusivamente de fatores que são subjetivos e não generalizáveis. O valor de troca de uma mercadoria deve poder ser determinado a partir de um parâmetro que não esteja sujeito às flutuações dos interesses 
e gostos de cada sujeito. O único modo de estabelecer o valor de troca de uma mercadoria seria isolando nela algum fator objetivo e mensurável, que segundo Marx seria encontrado nas horas de trabalho empregadas em sua produção.

Ao elevar o tempo de trabalho despendido na fabricação à categoria de principal parâmetro regulador das trocas, Marx está não só enfatizando a natural aptidão do fator trabalho a se prestar à quantificação e à objetividade, mas principalmente reconhecendo que somente o esforço dos homens pode criar valores. Basta tomarmos como exemplo um simples casaco de lã para nos darmos conta de que, para que este chegue a servir para nos proteger do frio, foi necessária a soma de muitos trabalhos: a criação de ovelhas, a tosquia, a fiação do tecido, etc. Sem o trabalho, o que teríamos seria uma natureza bruta diante da qual estaríamos completamente inermes, pois incapazes de extrair dela um proveito imediato. Mesmo os povos chamados coletores têm que trabalhar porque os objetos de que precisam não se encontram simplesmente ao alcance do braço, é necessário um esforço para encontrá-los e para aproveitá-los. É então graças ao trabalho que a matéria bruta da natureza se transforma em objetos destinados ao consumo humano. O trabalho representa o único modo de adicionar valor às coisas, pois é devido exclusivamente ao esforço humano que o meio ambiente pode ser modificado e submetido à fruição de nossa espécie. É por isso que, quando os homens vão ao mercado intercambiar seus bens, o tempo de trabalho despendido torna-se o grande balizador de seu valor de troca.

Não é por meio do dinheiro que as mercadorias tornam-se comparáveis e passíveis de serem trocadas. É antes o fato de as mercadorias serem todas elas materializações do trabalho humano o que as torna comensuráveis, sendo possível medir o quanto de trabalho cada uma encarna e a partir daí estabelecer uma proporção numérica entre elas. O dinheiro será apenas a expressão da quantidade de trabalho contido na mercadoria. "O dinheiro, como medida do valor, é a forma necessária de manifestar-se a medida imanente do valor das mercadorias, o tempo de trabalho" (MARX, 1867/2004, p.121).

Diferentemente de uma economia de subsistência, na qual o trabalhador visa prioritariamente a produção de bens para satisfazer suas próprias necessidades, ocupando a troca uma posição secundária, no capitalismo o processo de produção traz ao mundo objetos desde o início destinados ao mercado. O empresário não está preocupado em gozar diretamente dos produtos de sua indústria, já que não fará deles uso pessoal. Se ele produz botas, não é para consumi-las, mas sim pelo seu valor-de-troca. Do mesmo modo o trabalhador não usufrui diretamente do produto de seu trabalho, sua atividade visando, sobretudo, a remuneração das suas horas de trabalho em dinheiro.

Conforme foi dito, Marx concede ao trabalho o lugar de verdadeira fonte da riqueza. A grande novidade marxiana consistirá em desmontar o mito de que a 
riqueza do senhor capitalista se originou do fato de ele ser um self made man que trabalhou duro e se absteve de usar sua riqueza a fim de investi-la, enquanto os perdulários consumiam irresponsavelmente seus bens ou os preguiçosos se abstinham de trabalhar. A riqueza do capitalista advém do trabalho, sim, mas da apropriação do trabalho do operário, e essa exploração é tanto mais perniciosa quanto menos óbvia e intuitiva, merecendo, portanto, um trabalho de decifração.

Como, aqui, nos interessa desvendar as consequências psíquicas da exploração, é importante indicar de que modo particular o capitalismo a realiza.

Para produzir uma mercadoria são necessários três elementos: a matéria-prima (ou objeto sobre o qual se trabalha), os meios de trabalho num sentido amplo (máquinas, ferramentas, energia, etc.) e a força de trabalho. No capitalismo, o trabalhador não é proprietário nem da matéria-prima nem dos meios de trabalho, não podendo portanto deflagrar sozinho o processo de produção, o que o obriga a vender sua capacidade de trabalho para a classe proprietária. Disso resulta que a força de trabalho do operário torna-se também uma mercadoria entre outras - fato inédito até então, já que nem o escravo na Idade Antiga nem o servo na Idade Média vendiam seu trabalho.

Ao se tornar uma mercadoria, o trabalho passa a estar sujeito às mesmas leis que regulam a fixação do preço de qualquer mercadoria — a saber, seu valor de troca deverá ser determinado pelo tempo total necessário para a sua produção. Ora, sabe-se que o empregado não pode ser literalmente "fabricado" à maneira das outras mercadorias, já que ele não é um produto tal como o são um carro ou uma roupa. Se a força de trabalho não pode ser produzida no sentido rigoroso do termo, ela pode ser reproduzida. O valor do trabalho será então calculado visando garantir o indispensável para a sobrevivência do empregado, assegurando desse modo a reposição da energia por ele despendida. Esse montante pago ao trabalhador é o seu salário.

Segundo Marx, o valor final de um bem seria a soma dos trabalhos nele contida. Se, como foi dito, há basicamente três elementos envolvidos na produção, quanto de valor cada elemento agrega ao objeto? Os dois primeiros, que são a matéria-prima e os instrumentos, agregam o tempo que cada um deles levou para ser produzido. Já o último, o trabalhador, agrega o tempo que ele gasta para produzir o objeto.

Suponha-se agora que o capitalista remunerasse cada fator envolvido na produção de um bem (matéria-prima, instrumentos de trabalho, força de trabalho) pelo seu valor justo, ou seja, pelo valor que cada um deles transfere ao objeto. Os dois primeiros seriam pagos pelo tempo necessário para sua produção, o último (o operário) seria pago pelo tempo que ele leva para produzir o objeto. Ora, é óbvio que se o nosso empresário capitalista pagasse pela mercadoria final o equivalente à soma dos três fatores ele simplesmente não teria qualquer ganho! 
É necessário então que um desses fatores seja pago abaixo do seu valor: o trabalho do operário, cujo salário será inferior ao número de horas por ele acrescentadas aos objetos. Enquanto seu salário corresponde ao tempo mínimo de trabalho necessário para sua sobrevivência, sua jornada deverá ser estendida para um número de horas sempre superior a esse mínimo. Isso significa na prática que o operário vai consagrar algumas horas da sua jornada para trabalhar gratuitamente para o capitalista, de tal modo que sua remuneração será sempre inferior à sua jornada real. A diferença entre o tempo de trabalho efetivamente despendido por ele e o tempo de trabalho indispensável à manutenção de sua vida (seu salário) corresponde ao conceito marxista de mais-valia, que é justamente esse valor a mais cedido compulsoriamente pelo empregado ao capitalista: "o sobre-trabalho fornecido pelo operário é a única fonte do lucro capitalista e a única explicação possível deste lucro. O capital, ao comprar a força de trabalho, adquire uma mais-valia” (LEFEBVRE, 1960, p.94).

O que Marx aqui apresenta de completamente original é combater a explicação muito comum segundo a qual a fonte do ganho capitalista é o mercado, onde a exploração incidiria supostamente sobre o consumidor. Para Marx, quem é explorado é o trabalhador, não o consumidor, já que a extração de mais-valia não se dá no mercado, mas sim numa etapa anterior, ou seja, na produção, através da apropriação de parte das horas de trabalho do operário. Justamente por essa razão, mais-valia não é igual a lucro: o empresário pode eventualmente ter até mesmo prejuízo, pois o preço de uma mercadoria está sujeito em maior ou menor grau às contingências do mercado; mas ele não pode deixar de extrair mais-valia, pois esta é a condição necessária de funcionamento do capitalismo. A mais-valia é um conceito abstrato, que não pode ser reduzido ao lucro (embora obviamente acabe se exprimindo através dele).

\section{DA MAIS-VALIA AO MAIS-GOZAR}

Partindo de um referencial lacaniano, torna-se possível afirmar que essa transferência de parte das horas de trabalho do operário para o senhor capitalista funciona como uma renúncia ao gozo, uma perda pelo proletário da possibilidade de usufruir de parte dos produtos de seu trabalho. "O que Marx denuncia na mais-valia é a espoliação do gozo” (LACAN, 1969-1970/1992, p.76). Há perda de gozo na medida que o trabalhador passa boa parte de seu dia trabalhando além do que ele precisaria para sobreviver, na medida que ele tem sua existência roubada sacrificando preciosas horas de sua vida de mortal ao senhor capitalista. E o que há de mais espantoso no capitalismo é a maneira como essa espoliação do gozo é encoberta, tudo se passando como se o trabalhador recebesse pela sua jornada o preço justo.

Seguindo a tese lacaniana da castração simbólica, segundo a qual o ingresso na 
linguagem impõe uma perda de gozo, não devemos conceder ingenuamente ao capitalista uma posição de exceção e dizer que ele, sim, goza plenamente. Não se trata de afirmar que o capitalista tem acesso ao gozo vedado ao trabalhador, mas sim de que essa perda deva ser aí localizada de outra maneira. Em primeiro lugar porque o empresário não está preocupado em gozar dos produtos de sua indústria, já que não fará deles uso pessoal. Se ele produz botas, não é para consumi-las, mas sim pelo seu valor-de-troca: "assim, ele em um certo sentido renunciou ao gozo das botas por esse a mais de gozo que é a mais-valia!” (REGNAULT, 2006). Em segundo lugar, mesmo admitindo que o capitalista possa usar seu lucro na compra de jatinhos, bebidas caras e outros bens sofisticados — sabe-se que o sistema como um todo não pode sobreviver se todo o lucro for destinado ao consumo. O capital significa usar dinheiro para obter mais dinheiro, "dinheiro que se dilata, dinheiro que gera dinheiro” (MARX, 1867/2004, p.185), e isso só acontece se o empresário renunciar ao gozo imediato do lucro a fim de obter o a mais de gozo proporcionado por maiores lucros futuros.

O que há de original no capitalismo é precisamente o modo como a maisvalia passa a funcionar no interior do sistema: longe de ser apenas entesourada pelo capitalista ou revertida por ele em bens para consumo próprio, a maisvalia ingressa aqui num processo infinito: a finalidade do sistema é conseguir mais-valia, para quê? Para que este a mais de valor seja reinvestido no sistema, máquinas sejam compradas, empregados contratados, a fim de assegurar o quê? A produção de cada vez mais mais-valia... Como ensina Marx, "a circulação de dinheiro como capital tem sua finalidade em si mesma, pois a expansão do valor só existe nesse movimento continuamente renovado. Por isso, o movimento do capital não tem limites” (MARX, 1867/2004, p.183).

Não se trata aqui de um processo cuja finalidade é precisa e bem definida e que teria portanto uma conclusão. Trata-se antes de uma finalidade infinita, de um processo sem ponto de basta possível, onde não há limitações. Um processo que se inicia a partir de um imperativo de renúncia ao gozo, para em seguida reinvestir no sistema esse gozo sacrificado, a fim de conseguir ao final... ainda mais renúncia! Desse modo, o gozo vai paulatinamente se acumulando, produzindo efeitos, mas sem que ninguém possa dele se apossar na íntegra. Esse a mais de gozo faz o sistema girar, aquece a máquina da produção, mas sem que nenhum homem possa dele se dizer o possuidor. Como diz Quinet, o capitalismo promove "uma nova economia libidinal" ao "colocar a mais-valia no lugar da causa do desejo” (QUINET, 2007). É um a mais de gozo que vai se somando e promovendo efeitos sobre os sujeitos, que no entanto padecem de um gozo a menos...

Contudo, Lacan frisa que a perda de gozo sofrida pelo sujeito tem como contrapartida uma recuperação desse gozo num outro nível. Nomeia-se mais-gozar 
esse gozo paradoxal, gozo obtido precisamente no próprio ato de renunciar ao gozo. Se o sujeito experimenta um desperdício de sua energia, ao ceder parte daquilo que produziu ao capitalista (Lacan às vezes chama essa cessão de energia ao Outro de “entropia”), esse gozo que lhe foi subtraído será parcialmente restituído como um a mais de satisfação:

“De fato, é apenas nesse efeito de entropia, nesse desperdiçamento, que o gozo se apresenta, adquire um status. Eis por que o introduzi de início com o termo Mehrlust, mais-de-gozar. É justamente por ser apreendido na dimensão da perda (...) que esse não-sei-quê, que veio bater, ressoar nas paredes do sino, fez gozo, e gozo a repetir. Só a dimensão da entropia dá corpo ao seguinte — há um mais-de-gozar a recuperar." (LACAN, 1969-1970/1992, p.47/48)

Como situar essa recuperação de gozo? A parte de gozo que cabe ao sujeito será obtida por ele na injunção ao consumo à qual o mercado o incita. Desse modo, o gozo que lhe é negado será parcialmente restituído sob a forma de uma voraz fruição de mercadorias, lançando-o paradoxalmente em um estado de falta constante, que ele, por engano, acredita poder ser sanada pelos novos produtos a serem lançados...

O capitalismo tem todo o interesse em fomentar a insatisfação nos sujeitos capturados por esse discurso, a importância dessa promoção do descontentamento encontrando-se ligada a uma necessidade estrutural do sistema. Expliquemos melhor. A maior parte da mais-valia extraída pelo capitalista deverá se transformar em capital, em dinheiro usado para ganhar mais dinheiro, o que significa: reinjetá-lo no sistema, proporcionando uma ampliação das forças produtivas. A consequência dessa expansão circular será um absurdo aumento do volume de mercadorias, gerando para o sistema a necessidade de escoá-las, de se livrar delas. É preciso que a produção incessante se faça acompanhar por uma expansão crescente da demanda (vem daí a famosa tese marxista, utilizada por Lacan, de que a oferta cria a demanda). A demanda incessante que o sujeito faz por novas mercadorias e sua insatisfação com que as que já tem significa que o discurso capitalista tem êxito em transformar a insatisfação constitutiva do desejo humano em uma insatisfação comandada pelo mercado.

Tem lugar então um processo de obsolescência planejada das mercadorias, correspondendo à necessidade de criar sempre novas demandas por parte dos consumidores. A obsolescência decorre não só do fato de as mercadorias serem propositadamente feitas com materiais de pouca durabilidade, mas sobretudo pela expectativa da próxima novidade, gerada pelos mecanismos de propaganda. Isso se dá porque 
“[...] a durabilidade dos objetos produzidos é o maior obstáculo ao processo de reposição, cuja velocidade em crescimento contínuo é a única coisa permanente que resta onde se estabelece o processo de produção. A mentalidade do animal laborans se tornou, assim, tão predominante no mundo moderno que o aumento da produtividade é diretamente proporcional ao crescimento do desperdício. Os bens são produzidos como se fossem "efeitos colaterais" da produção, pois são destinados, o mais rapidamente possível, ao consumo.” (ALVES NETO, 2007, p.168-169)

A passagem menciona o importante problema do desperdício gerado pelo modo de vida capitalista. A voracidade do sistema em ampliar constantemente a produção torna todo bem potencialmente descartável, acarretando um custo ambiental gigantesco, já que passamos a consumir muito mais do que o necessário para a manutenção da vida. Cria-se uma imensa demanda pelo supérfluo, quando qualquer objeto torna-se transitório e fugaz, gerando um desperdício duplo: primeiro, do nosso tempo de trabalho, que passa a estar devotado à obtenção de uma mercadoria cujo prazo de validade encontra-se antecipadamente vencido; segundo, dos recursos naturais, acarretando um sacrifício em termos ecológico que ameaça a nossa sobrevivência na Terra. O resultado é que o sujeito passa a habitar um mundo já previamente condenado à dejeção.

\section{CONSEQUÊNCIAS PSÍQUICAS DO TRABALHO NO CAPITALISMO}

Há em Marx certa visão do trabalho como espaço de realização humana ou, em linguagem psicanalítica, como um lugar em que o sujeito se constitui como desejante, já que através do trabalho o homem submete a sua atividade a fins e ingressa em certo projeto que organizará sua vida. Contudo, há também em Marx uma visão negativa, ligada ao trabalho sob a égide do capitalismo, como a que encontramos em suas proposições sobre o trabalho alienado (MARX, 1844/2004). O trabalhador assalariado foi pouco a pouco perdendo a capacidade de iniciar o processo de produção e de conferir finalidade a ele. Sua participação será cada vez mais limitada a uma peça da engrenagem. Desde a Revolução Industrial, quando foram introduzidas as máquinas-ferramentas, o trabalhador perdeu o pouco espaço que lhe restava para exibir seu talento pessoal, suas habilidades ou sua criatividade, "o colocar em marcha os meios de trabalho já não depende mais da aptidão pessoal do trabalhador. A organização da produção passa a ser completamente independente das características da força humana de trabalho" (HARNECKER, 1973, p.55). Em suma, a singularidade do trabalhador vai sumindo, devorada pela homogeneização do mundo e pelo apagamento das diferenças que o capitalismo vai produzindo.

O trabalhador no capitalismo produz uma mercadoria na qual ele não pode depositar nada de propriamente seu — já que qualquer um pode fazer igual, 
basta apertar o botão e tudo se arranja, a máquina faz o resto —-, nem reconhecer nela uma expressão de sua marca pessoal, já que todos os produtos industriais são uniformes e padronizados.

Na verdade, mais do que limitar e tornar dispensável qualquer característica singular do trabalho, o que o capitalismo torna verdadeiramente supérfluo é o próprio trabalhador, que passa a conviver com uma terrível ameaça no horizonte: a ameaça do desemprego. É preciso reduzir custos e diminuir o peso do 'fator humano' na folha de pagamentos, ou seja, aumentar a exploração. Uma das formas para isso é o prolongamento da jornada de trabalho, que contudo esbarra sempre em "um limite fisiológico e um limite político imposto pela luta da classe obreira” (HARNECKER, 1973, p.58). A estratégia alternativa é investir na automação, tornando o trabalho mais produtivo e dispensando uma parte da mão-de-obra. Parece que o sonho de todo empresário passa a ser o de ter um robô que faça todo o serviço e prescinda do auxílio humano (fantasia compreensível, exceto pelo fato de ela omitir a necessidade de um empregado capaz de projetar o robô...). O resultado é a redução dos postos de trabalho e o desemprego crescente.

Pode-se argumentar que o desemprego acaba sendo contrabalançado por outros fatores, sobretudo porque o capitalismo em sua expansão termina abrindo novas frentes, novas empresas, oferecendo novos produtos e precisando de mais mão-de-obra... Embora tal tese não seja inteiramente falsa, é preciso lembrar que o trabalhador não tem uma labilidade infinita, sua capacidade de transmutação sofre restrições. Como diz Zizek:

“(...) há uma tendência cada vez maior a que não se tenha um emprego permanente pela vida afora, mas se mude de emprego a cada dois ou três anos. Alguns ideólogos pós-modernos comemoram isso como uma nova libertação, no sentido de que não se tem uma identidade fixa: para usar uma expressão da moda, tem-se uma “carteira de subjetividades”. Essa é uma típica operação ideológica pós-moderna, na qual o horror de o sujeito nunca saber ao certo se terá ou não um emprego é vendido como a nova liberdade. O indivíduo não se fixa numa identidade; tem de se reinventar a cada dois ou três anos.” (ZIZEK \& DALY, 2006, p.182)

O problema é que nem a nossa possibilidade de reinvenção é infinita, nem o processo de criação de novos postos segue num ritmo tão veloz quanto o de sua extinção. "Portanto, essa camada de desempregados já não é simplesmente um excedente, mas algo estruturalmente inscrito. A classe trabalhadora divide-se entre os que têm e os que não têm um emprego" (ZIZEK \& DALY, 2006, p.182).

Aplicando aqui a lógica freudiana da castração, quem tem emprego vive atormentado pelo temor da sua perda, quem não tem quer desesperadamente ter, e 
se há algo que unifica a todos é sentimento de absoluta superfluidade, em que todos são ou podem vir a ser os rejeitos que não foram absorvidos pelo processo de produção. Reencontramos aqui a já mencionada dejeção, que no capitalismo afetará o homem em suas três esferas de relacionamento: com a natureza, com os outros homens e consigo mesmo.

\section{CONSEQUÊNCIAS PSÍQUICAS DO CONSUMO NO CAPITALISMO}

Reservaria a relação de consumo um destino mais feliz para o sujeito, uma vez que o consumo parece ser o lugar no qual o trabalhador consegue recuperar um pouco do gozo perdido? Vimos que por sua lógica interna o capitalismo encontra-se predestinado a fomentar nos sujeitos uma falta incessante, uma insatisfação constante, que em contrapartida deve vir sempre acompanhada pelo gozo de algum gadget, objeto descartável que produz uma fruição curta e rápida. Essa obsolescência dos objetos é típica do capitalismo e é importante notar que sem isso ele não poderia sobreviver, pois a uma oferta sempre crescente de mercadorias deve corresponder uma demanda sempre renovada. O resultado é que a mercadoria já chega ao mercado natimorta; ela está fadada a ser apenas um momento de um processo em que o consumidor deve devorá-la para logo em seguida desprezá-la. Como a acumulação de capital é um processo sem ponto de basta, cujo objetivo é acumular cada vez mais capital, a mercadoria representa um mero acidente desse processo, proporcionando um gozo pontual, que embora necessário para levar o processo para a frente é por isso mesmo feito para ser breve.

A relação de consumo é elevada ao zênite no céu do capitalismo e vai se espraiando para todas as esferas da existência, a ponto de os homens passarem a interpretar-se a si próprios como mercadoria também, no sentido de algo para ser usado e descartado. Lacan chega a dizer, não sem ironia, que os trabalhadores "são eles próprios produtos, como se diz, consumíveis tanto quanto os outros. Sociedade de consumo, dizem por aí. Material humano, como se enunciou um tempo - sob os aplausos de alguns que ali viram ternura" (LACAN, 196970/1992, p.30). Na verdade aqueles mesmos que Marx tratava como representantes da classe dominante são arrebatados pelo movimento que transforma todos eles em consumidores, razão que levou Lacan a afirmar que no capitalismo todos são proletários (LACAN, 1974).

Desse modo não é só com os objetos que instauramos uma relação de consumo mas também com os homens. Como afirma Quinet:

"O discurso capitalista efetivamente não promove o laço social entre os seres humanos: ele propõe ao sujeito a relação com um gadget, um objeto de consumo curto e rápido. Esse discurso promove um autismo induzido e um empuxo-ao-onanismo 
fazendo a economia do desejo do Outro e estimulando a ilusão de completude não mais com a constituição de um par, e sim com um parceiro conectável e desconectável ao alcance da mão.” (QUINET, 2007)

Afirmar que o discurso capitalista não promove o laço social não significa dizer que o laço social está ausente no capitalismo, mas sim que nele há uma tendência ao seu enfraquecimento. Ou, segundo uma feliz formulação de Frédéric Declercq, o discurso capitalista teria "efeitos antissociais" (DECLERCQ, 2006, p.75). Isso porque a condição para haver laço social é o reconhecimento de que somos incapazes de pensar, dizer e fazer tudo sozinhos. Em função de nossa incompletude, precisamos nos dirigir ao Outro a fim de que este suplemente nosso pensamento, ou que aponte nossas falhas de pensamento. Se o discurso capitalista enfraquece o laço social é porque nele já não nos dirigimos ao Outro como uma instância que nos faça ir além de nós mesmos, ultrapassando o que poderíamos fazer sozinhos. O lugar dos nossos "parceiros” passará a ser o de simples objetos de fruição, que não acrescentam nem retiram nada ao nosso saber, em suma, que não nos tiram da idiotia. Com esses parceiros, as chances de um encontro com o real são mínimas, não sendo exagero afirmar que nossos "encontros" se reduzirão a uma masturbação a dois.

Em suma, ao conectar o sujeito a gadgets, objetos de consumo parciais que trazem uma satisfação fugaz e que rapidamente se tornam dejetos; e ao favorecer a aparição de sujeitos que tratam uns aos outros de modo intrumental, como se cada um fosse apenas um meio para obter um fim, o capitalismo acaba favorecendo uma ligação perversa ao Outro, o que em certo sentido desfavorece a formação do laço social.

Recebido em 11/9/2007. Aprovado em 25/2/2008.

\section{REFERÊNCIAS}

ALVES NETO, R. (2007) "Mundo e acosmismo na obra de Hannah Arendt”. Tese de doutorado, Programa de Pós-graduação em Filosofia, Departamento de Filosofia da PUC-Rio.

DÉCLÉRCQ, F. (2006) Lacan on the capitalist discourse: its consequences for libidinal enjoyment and social bonds. Psychoanalysis, Culture \& Society, n. 11. Palgrave Macmillan, p.74-83. Disponível em: www.palgravejournals.com. Acesso em: 4/8/2007.

HARNECKER, M. (1973) Conceitos elementais do materialismo histórico. São Paulo: Edições Sociais. 
LACAN, J. (1969-1970/1992) O seminário livro 17, O avesso da psicanálise. Rio de Janeiro: Jorge Zahar. Seuil.

( 1968-1969/2006) Le Séminaire livre XVI, D'un Autre à l'autre. Paris:

(1974) Conferência proferida no Centro Cultural Francês, em 30 de março de 1974. Inédito.

LEFEBVRE, H. (1960) O marxismo. São Paulo: Difusão Europeia do Livro.

MARX, K. (1844/2004) Manuscritos econômico-filosóficos. São Paulo: Boitempo.

(1867/2004) O capital: crítica da economia política. Livro I, v. 1. Rio de Janeiro: Civilização Brasileira.

QUINET, A. "A ciência psiquiátrica nos discursos da contemporaneidade”. Disponível em: lacanian.memory.online.fr. Acesso em: 2/9/2007.

REGNAULT, F. “Le Marx de Lacan”. Disponível em: www.causefreudienne.net. Acesso em: 12/2/2007.

ZIZEK, S. \& DALY, G. (2006) Arriscar o impossível: conversas com Zizek. São Paulo: Martins Fontes.

Rosane Zétola Lustoza

rosanelustoza@yahoo.com.br 